\title{
PROCEEDINGS OF THE PATHOLOGICAL SOCIETY OF GREAT BRITAIN AND IRELAND
}

The 164th meeting of the Society was held by the United Medical and

Dental Schools of Guy's and St Thomas's Hospitals at The Wolfson Conference Centre

Royal Postgraduate Medical School, Hammersmith Hospital, London on January 8-10 1992

SYNOPSES OF PAPERS OF MICROBIOLOGICAL INTEREST

SYMPOSIUM: PCR IN THE DIAGNOSIS OF INFECTIOUS DISEASE

Chairman: G. French

PCR: A BACTERIOLOGIST'S DREAM OR NIGHTMARE?

\section{P. Quirke}

Academic Unit of Pathology, University of Leeds, Leeds LS2 9JT

The polymerase chain reaction has produced a potentially powerful new approach to bacteriology. This technique has advantages and disadvantages and offers many benefits if applied carefully. Advantages include its rapidity, specificity and sensitivity. It allows the identification of pathogens from amongst many other bacteria and also the presence of toxins or antibiotic resistance carriage. The ability to synthesise your own primers from published sequences removes the difficulty of obtaining probes from other workers. The disadvantages are important and must be recognised prior to interpretation of a result. False positives, non-pathogenic numbers of bacteria, presence of inhibitors of amplification, the requirement to identify a specific pathogen and the necessity for specific sequence information are all problems. These are not insurmountable but they must be considered.

A range of bacterial PCRs have been described in the literature. We have concentrated our work on Helicobacter pylori $(\mathrm{Hp})$ and mycobacteria. A $16 \mathrm{~S}$ rRNA PCR for Hp has been developed and early investigations of its value in gastric disease and other situations were described. Selected examples of the other uses of bacterial PCRs were discussed including the use of universal primers and toxin detection.

\section{CAN PCR IMPROVE OUR DIAGNOSIS OF} MYCOBACTERIAL INFECTIONS?

\section{P. M. Hawkey}

Department of Microbiology, University of Leeds, Leeds $L S 29 J T$

Through public health and therapeutic initiatives, the incidence of tuberculosis has declined rapidly in the UK in the last 40 years. Sporadic cases and clusters of infection do still occur in both the indigenous and immigrant population with a much higher incidence in the immunosuppressed. Laboratory diagnosis relies heavily on direct microscopy of stained specimens and culture which takes up to 8 weeks. Commercial DNA probes for 16S rRNA sequences of mycobacteria are available but they are complicated to use and lack sensitivity. The specificity combined with extreme sensitivity of PCR-based amplification techniques makes them interesting candidates for the non-cultural identification of mycobacteria. Over the last 2 years a large number of PCR-based protocols for detecting mycobacteria has been published. Some of the nucleic acid targets that have been used are: (i) amplification of genes or parts of those genes encoding antigens such as the $65-\mathrm{kDa}$ heat shock protein,
MPB64 protein and antigen b; (ii) amplification of $16 \mathrm{~S}$ rRNA and cDNA encoding it ; (iii) amplification of repeated sequences. The results of using these various systems with clinical specimens were discussed. As expected, all investigators have been able to rapidly detect nucleic acid derived from mycobacteria in samples which are negative by microscopy and culture. By using appropriate primers and sometimes oligonucleotide probes to confirm the identify of the amplified product, identification of species is also possible. It is clear that great care is required to prevent contamination of samples. A control for the presence of inhibitors of amplification is used by the more careful workers and usually takes the form of DNA derived from a cloning vector such as pUC 19 together with primers to amplify a suitable sequence, this is added to the sample. Standardisation of the DNA extraction technique is important as some groups have had trouble with falsenegative results due to poor bacterial lysis. At least two independent pairs of primers should be used as some specimen/primer combinations fail to amplify. Although the technique is technically sophisticated and requires an investment in equipment and expertise, it offers an exciting advance in the diagnosis of tuberculous disease, particularly in meningitis.

THE APPLICATION OF PCR TO THE DIAGNOSIS AND MANAGEMENT OF TOXOPLASMOSIS

\section{R. E. Holliman}

Public Health Laboratory, St George's Hospital, Blackshaw Road, London SW17 OQT

Toxoplasmosis is a life-threatening opportunist infection of the immunocompromised. In this group of patients, serological investigation is unreliable and parasite isolation may not produce results with sufficient rapidity. Consequently, a DNA-based assay was developed for the detection of Toxoplasma gondii. The assay involves sequential amplification of part of the P30 gene with nested primers. Following gel electrophoresis, the amplified DNA fragment can be detected either directly on the gel or by Southern hybridisation with radioactive or non-radioactive DNA probes. In-vitro assessment showed the assay could detect as little as $0.05 \mathrm{pg}$ of toxoplasma DNA, which corresponds to a single organism, both in the presence and absence of contaminating human DNA. DNA of other protozoan species was not amplified, indicating the specificity of the assay. Toxoplasma DNA was detected in brain tissue of laboratory-infected mice. PCR has been used to diagnose toxoplasmosis in bone marrow graft recipients and AIDS patients and the assay has been applied to the investigation of toxoplasmosis associated with pregnancy.

PCR represent a method of potential value for the investigation and management of toxoplasma infection of 
the immunocompromised. Further studies are required to define the relative merits of this technique in comparison with established diagnostic methods.

\section{RAPID DIAGNOSIS OF HER PES ENCEPHALITIS BY PCR}

\section{P. E. Klapper and G. M. Cleator}

North Manchester Regional Virus Laboratory, Booth Hall Children's Hospital and Department of Pathological Sciences, University of Manchester

Controlled studies have shown that prompt acyclovir treatment leads to significant reduction in the mortality and morbidity of severe herpes simplex encephalitis (HSE). Because acyclovir is perceived as being a compound of low toxicity there has, in recent years, been a reluctance to perform brain biopsy in pursuit of diagnosis. The virologist has, therefore, had to develop "non-invasive" strategies in an attempt to provide early diagnosis of HSE.

Using the polymerase chain reaction (PCR) to amplify Herpesvirus simplex genetic material (a conserved region within the thymidine kinase gene) we have developed a method which promises early, non-invasive, diagnosis of HSE. In a retrospective study, we examined 39 samples of CSF taken during the first 10 days of illness ( 35 patients with virologically confirmed $\mathrm{HSE}$ ): 36 CSF samples were PCR positive, three were PCR negative. Two of the negative samples were taken on the day of onset of neurological illness, one was taken on day 2; 109 non-HSE CSF samples gave negative results.

To determine the true value of PCR as a routine diagnostic procedure, we initiated a prospective study: 150 acute CSF samples from 126 patients with suspected HSE have been examined during a 9-month period. Twelve samples (11 patients) were PCR-positive, 138 were negative. Amongst the negative results we know of no "false negatives" and among positive results we have detected two probable false positives. Detailed follow up of all results was presented. PCR appears to offer a valuable non-invasive method for acute stage diagnosis of herpes encephalitis and an important aid in the differential diagnosis of conditions which mimic herpes encephalitis.

PCR AS AN AID TO DIAGNOSIS OF

CYTOMEGALOVIRUS INFECTION

\section{R. P. Eglin, S. J. Read* and A. T. Hattersley†}

Department of Virology, Public Health Laboratory, Leeds LS15 7TR, *Department of Virology, Public Health Laboratory, Oxford OX3 9DU and +Department of Haematology, John Radcliffe Hospital, Oxford OX3 9DU

Increasing numbers of organ transplants and AIDS patients, and specific chemo- and immunotherapy for CMV has resulted in pressure to produce rapid, sensitive and specific identification of CMV infections. If PCR is to be accepted for routine diagnostic use it must be reliably better than other methods currently available.

An in-situ hybridisation (ISH) method with photobiotinlabelled CMV DNA had a sensitivity of 10-40 CMV copies/ cell and a processing time of $5 \mathrm{~h}$. PCR used the technique of nested CMV IE primers, with two rounds ( 40 and 30 cycles) giving a sensitivity of three CMV copies/sample.

PCR detected CMV sequences in a range of clinical specimens, even when diluted 1000 -fold, in samples shown to be infected by ISH. There are reports of the detection by PCR of latent CMV in lymphocytes of CMV seropositive healthy individuals. This makes the clinical significance of CMV detection in blood samples unclear at present.

There are problems common to all PCRs-failure of amplification, contaminating sequences, accurate quantification of the initial CMV copy number and determination of cell types involved-which can pose considerable problems in the clinical interpretation of PCR results.

\section{PCR IN THE DIAGNOSIS OF PNEUMOCYSTIS CARINII PNEUMONIA}

\section{A. E. Wakefield and J. M. Hopkin*}

Molecular Infectious Diseases Group, Department of Paediatrics, Institute of Molecular Medicine, John Radcliffe Hospital, Oxford OX3 9DU and *Olser Chest Unit, Churchill Hospital, Oxford $O X 37 \mathrm{LJ}$

The opportunist fungus Pneumocystis carinii is the major cause of fatal pneumonia in immunosuppressed individuals particularly AIDS sufferers. We have cloned the DNA from $P$. carinii, confirmed by characteristic in-situ hybridisation patterns. Using the sequence of the gene coding for the large subunit of the mitochondrial ribosomal RNA, we have designed primers which efficiently amplify both rat-derived and human-derived $P$. carinii. We have tested these primers using PCR with DNA from other pulmonary pathogens and over 100 closely related organisms and demonstrated that the primers are entirely specific to $P$. carinii. We have increased the sensitivity of detection of the products of DNA amplification by oligoblotting, with an internal oligonucleotide as a probe.

We have applied these methods to the detection of $P$ carinii in bronchoalveolar lavage samples and in noninvasive induced sputum samples from over 100 episodes of acute respiratory illness. No $P$. carinii was detected in samples from immunocompetent individuals. In the immunosuppressed, a strong DNA amplification signal correlated with clinical $\boldsymbol{P}$. carinii pneumonia, whereas a weak signal was an indication of low, sub-clinical levels of infection.

We find that DNA amplification for $P$. carinii offers great sensitivity and specificity and that the results can be correlated with clinical disease.

\section{4th C. L. Oakley Lecture}

CANDIDA HSP 90: LINK BETWEEN PROTECTIVE AND AUTO IMMUNITY

Ruth C. Matthews

Department of Medical Microbiology, University of Manchester, Oxford Road, Manchester M139PT

Heat shock proteins are thought to play a role in the aetiology of autoimmune diseases, but are also common targets for the immune response to many infections. Patients recovering from systemic candidosis produce antibodies to Candida albicans HSP 90, both to species-specific epitopes and, more commonly, epitopes shared with human HSP 90. One such autoreactive antibody was protective in a mouse model of systemic candidosis. 
POSTERS AND DEMONSTRATIONS

AMPLIFICATION AND CHARACTERISATION OF GENE FRAGMENTS ENCODING GLOBAL REGULATORY PROTEINS FROM LISTERIA MONOCYTOGENES, YERSINIA ENTEROCOLITICA AND YERSINIA PSEUDOTUBERCULOSIS

Susan M. Colby, Rachael R. Cubberley and B. W. Wren Department of Medical Microbiology, St Bartholomew's Hospital Medical College, West Smithfield, London EC1A $7 B E$

In order to potentiate disease, Listeria monocytogenes, Yersinia enterocolitica and $Y$. pseudotuberculosis have to survive a range of extracellular and intracellular environments. Recently, it has been demonstrated that many bacterial factors are controlled by a limited number of conserved two-component global regulatory proteins which respond to environmental stimuli. Often the global regulatory protein co-ordinately controls the transcription of a number of genes directly involved in virulence. Recent studies have shown the regulatory protein $\mathrm{PhoP}$ to be essential for the survival of Salmonella typhimurium in macrophage cells and the related regulatory proteins OmpR to be associated with the invasiveness of Shigella flexneri. Furthermore, $S$. typhimurium strains bearing mutations in the pho $\mathrm{P}$ and $o m p \mathrm{R}$ genes have been found to be highly attenuated in BALB/c mice. The aim of this study was to amplify, sequence and mutate the $p h o \mathrm{P}, o m p \mathrm{R}$ and other global regulatory gene equivalents from $L$. monocytogenes, Y. enterocolitica and $Y$. pseudotuberculosis.

Using published sequence data from the $S$. typhimurium and Escherichia coli pho $\mathbf{P}$ and $o m p \mathbf{R}$ genes, degenerate primers were synthesised and used in the PCR to amplify the equivalent gene fragments from $L$. monocytogenes, $Y$. enterocolitica and $Y$. pseudotuberculosis. The expected 341bp fragment was amplified from the genomic DNA of all three species. Sequence analysis of the cloned fragments revealed that several independent members of the family global regulatory genes had been amplified. These included three clones each from $L$. monocytogenes and Y.enterocolitica, and five clones from $Y$. pseudotuberculosis. The derived amino-acid sequences from these clones revealed $26-77 \%$ homology to PhoP and $28-52 \%$ homology to OmpR.

The genes encoding the global regulatory proteins will be mutated and the resultant mutants will be compared to the wild-type strain. The mutational analysis of such genes should provide a range of $L$. monocytogenes and Yersinia strains for pathogenicity, immunological, attenuation and vaccination studies.

RAPID IDENTIFICATION OF TOXOGENIC CLOSTRIDIUM DIFFICILE BY POLYMERASE CHAIN REACTION WITH TOXIN A AND B SPECIFIC PRIMERS

B. W. Wren, N. B. Castledine and Soad Tabaqchali

Department of Medical Microbiology, St Bartholmew's Hospital Medical College, West Smithfield, London EC1A 7BE

Clostridium difficile is the aetiological agent of pseudomembranous colitis and antibiotic-associated diarrhoea in man. The pathogenicity of $C$. difficile is, in part, related to the production of at least two toxins, toxin $A$, an enterotoxin, and toxin B, a cytopathic toxin. Currently, diagnosis depends on the isolation and identification of the organism, which takes up to $72 \mathrm{~h}$ and/or the demonstration of toxins in faecal specimens of patients by tissue culture or ELISA techniques. More rapid diagnosis is essential to enable prompt treatment. The aim of this study was to develop a rapid, sensitive and specific method for the identification of toxigenic $C$. difficile strains by PCR with primers specific for toxins $A$ and $B$.

Samples for PCR experiments consisted of simple boilates from characterised $C$. difficile strains which were tested for toxigenicity by tissue culture. Standardised PCR conditions were used in all experiments, with 30 cycles and an annealing temperature of $45^{\circ} \mathrm{C}$. Amplified PCR products were electrophoresed for $1 \mathrm{~h}$ on agarose $1 \%$ gels and visualised under UV light. The total time for the procedure, including sample preparation, was 3-4 h.

Results with the toxin A primers revealed that 201 out of 202 toxigenic strains and none of the 35 non-toxigenic strains were PCR positive. Results with the toxin $B$ primers revealed that all 202 toxigenic strains produced the expected 591-bp product by PCR analysis which was absent for all 35 nontoxigenic strains. These results suggest that the presence of either toxin gene is a good indicator of toxin expression. Analysis of 45 other bacterial species, including 14 clostridial species, were PCR negative with the exception of three toxigenic $C$. sordellii strains which were positive with the toxin A primers. The PCR appeared three times more sensitive with the toxin A primers compared with the toxin $B$ primers and was successful when as few as 20 toxigenic bacteria were present. The PCR method could detect this level of toxigenic $C$. difficile even in the presence of $10^{8}$ other bacteria.

The PCR-based method, which does not require hybridisation techno'ogy or the use of radioactivity, should be useful for the rapid identification of toxigenic $C$. difficile strains from pure and mixed culture and could be applied to cultured specimens.

\section{APPLICATION OF PCR WITH MIXED \\ OLIGNUCLEOTIDE PRIMERS TO AMPLIFY, CLONE \\ AND SEQUENCE htrA GENE FRAGMENTS FROM \\ YERSINIA ENTEROCOLITICA AND CAMPYLOBACTER JEJUNI}

Rachael R. Cubberley, Susan M. Colby and B. W. Wren

Department of Medical Microbiology, St Bartholomew's Hospital Medical College, West Smithfield, London EC1A $7 B E$

In response to stress, all organisms apparently upregulate the synthesis of specific groups of proteins which maintain the integrity of the cell. Many of these so-called heat shock proteins are highly conserved among prokaryotic and eukaryotic organisms, reflecting their importance for the well-being of the cell. There is a wealth of recent evidence to suggest that heat shock proteins also play an important role in infections of a range of invasive bacteria. In particular, HtrA, a serine protease, has been found to be important in Salmonella typhimurium virulence. $S$. typhimurium $\mathrm{HtrA}$ negative mutants have a decreased ability to survive oxidative stress which may be indicative of the inability of these mutants to survive the oxidative bursts produced by macrophages in response to invasion by foreign organisms. Investigation of the Yersinia enterocolitica and Campylobacter jejuni htrA gene equivalents should provide a better understanding of the survival mechanisms of these organisms in the host and of host immune responses.

We have developed an adaptation of the basic PCR, with mixed oligonucleotide primers (PCRMOP), for the convenient amplification of conserved gene fragments from a range of organisms. The application of PCRMOP allows the detection of genes in one species with sequence data from a homologous gene of protein from another species. Using HtrA amino-acid sequence data derived from Escherichia coli and $S$. typhimurium, degenerate primers were 
designed and used in the PCR with $0.1 \mu \mathrm{g}$ of genomic DNA from $Y$. enterocolitica and $C$. jejuni. The expected PCR products of $476 \mathrm{bp}$ were amplified for both organisms and subsequently cloned into pUC19 and sequenced. The amplified $Y$. enterocolitica and $C$. jejuni gene fragments revealed 88 and $75 \%$ homology with the derived amino acid from $S$. typhimurium $\mathrm{HtrA}$, respectively. Y. enterocolitica and C. jejuni htr A mutants will be constructed which will be be useful for pathogenicity, immunological, attenuation and vaccination studies.

The PCRMOP method described has several advantages over conventional methods employing amino-acid sequence data to study genes. It is quicker and easier than the use of degenerate oligonucleotide probes and filter hybridisation methods and can tolerate far greater degeneracies than these techniques. The PCRMOP technique is rapid, convenient and makes it possible to specifically study determinants involved in virulence and gene regulation.

\section{PCR AND THE EPIDEMIOLOGY OF BORRELIA} BURGDORFERIIN SCOTLAND

\section{S. M. Curtin, A. A. Cunningham* and T. H. Pennington}

Department of Medical Microbiology, Foresterhill, Aberdeen $A B 92 Z D$ and $^{*}$ Veterinary Science Research Group, Institute of Zoology, Zoological Society, London NWI 4RY

Lyme disease is caused by the spirochaete Borrelia burgdorferi and transmitted to animals and man by the bite of infected ixodid ticks. Much of the work on Lyme disease has been conducted in the USA where the white footed mouse has proved to be the main animal reservoir for the spirochaete. Although Lyme disease, as it is now known, was first described in Europe in 1909, the role as reservoirs, of our indigenous mammal population has not been fully investigated.

The Isle of Rum on the west coast of Scotland was chosen as an enclosed study site, having an abundance of ticks and a large deer population. Initially, ticks were collected and assayed by PCR, to check for the presence of $B$. burgdorferi. When this was confirmed, deer samples including spleen, kidney, liver, ear punch, urinary bladder and synovial tissue were collected and subjected to a similar assay. By refining our assay we were able to determine the incidence of $B$. burgdorferi infection in both adult and nymphal ticks, and locate the infected tissues in the deer tested for the first time.

Having shown PCR to be an effective tool for investigation, we have broadened our study in the hope of discovering the true story of Lyme disease in Scotland.

\section{RAPID DETECTION OF ALTERED PENICILLIN BINDING PROTEINS IN NEISSERIA MENINGITIDIS BY THE POLYMERASE CHAIN REACTION}

A. F. Maggs, P. E. Carter*, T. H. Pennington* and H. M. Dick

Medical Microbiology Department, University of Dundee and * Department of Medical Microbiology, University of Aberdeen

Meningococcal resistance to penicillin has been a relatively rare phenomenon. Recently, however, there has been an increase in the number of reported cases of penicillin resistance in these bacteria. Resistance can be due to either the production of a $\beta$-lactamase or alteration of penicillin binding protein 2 (PBP-2) which has a decreased affinity for penicillin. We have been developing PCR as a tool for the rapid identification of the altered $\mathrm{PBP}-2$ and penicillin resistance.

Strains of Neisseria meningitidis from a number of geographical sources were examined by PCR with primers specific for PBP-2. Samples included NCTC control strains and clinical samples with a range of MICs to penicillin of $0.01 \mu \mathrm{g} / \mathrm{ml}$ (fully sensitive) to $0.64 \mu \mathrm{g} / \mathrm{ml}$ (relatively insensitive). Strains which were fully sensitive to penicillin produced almost identical results independent of serogroup and area of isolation. In contrast, strains with a reduced penicillin sensitivity showed a variety of patterns (including no amplification at all) with primers derived from the $N$. meningitidis gene. Several isolates were amplified with primers derived from $N$. flavescens as well as $N$. meningitidis. These results give further support to the idea of multiclonal penicillin resistance and are in accord with the notion of a mosaic gene structure for the penicillin resistant PBP-2.

\section{DETECTION OF STAPHYLOCOCCAL ENTEROTOXINS BY THE POLYMERASE CHAIN REACTION}

T. Purcell, F. M. Thomson-Carter and P. E. Carter

Department of Medical Microbiology, University of Aberdeen, Foresterhill, Aberdeen

Staphylococcal enterotoxins have long been recognised for their emetic and food poisoning abilities. They have recently been shown to have a powerful mitogenic effect on cells involved in the immune response. This effect is due to their ability to bind to the T-cell receptor and to HLA class 2 antigens on the surface of these cells inducing a proliferation response. Until recently, methods for the detection of the enterotoxins were based on growth of bacteria and immunological techniques for measuring toxin production. Five major serological groups have been described, labelled A-E. In this study, clinical and nonclinical isolates of staphylococcal species including the coagulase-negative staphylococci and positive controls were examined by the polymerase chain reaction for the presence of the enterotoxin genes.

Primers specific for each of the five enterotoxin genes were synthesised based on previously published sequences. Using restriction endonuclease digestion, each set of primers was shown to be specific for the enterotoxin gene in question. Initial studies have shown that the presence of the enterotoxin genes in any particular isolate can be determined from a single colony on a plate. There is a wide degree of diversity as to the presence of the various enterotoxin genes. We are currently investigating the different enterotoxin profiles of clinical isolates and also among the staphylococcal population of the normal body flora.

PCR OF BORRELIA BURGDORFERIIN HUMAN SAMPLES AS A VALID TOOL FOR THE DIAGNOSIS OF LYME DISEASE

\section{S. M. Curtin, G. Thomson* and T. H. Pennington}

Department of Medical Microbiology, Foresterhill, Aberdeen $A B 92 Z D$ and ${ }^{*}$ Department of Microbiology, Ninewells Hospital, Dundee DDI $9 S Y$

Lyme disease is a recently recognised disease affecting both animals and man. It is caused by the spirochaete Borrelia burgdorferi and transmitted by the bite of ixodid ticks. On initial infection, a characteristic rash known as Erythema Chronicum Migrans (ECM) appears around the tick bite. A flu-like illness generally accompanies this rash. Weeks or months later a second stage of the disease including meningitis and carditis may develop. Late stages of the disease, represented by an arthritis not unlike rheumatoid arthritis, may occur many years after the initial infection.

Precise diagnosis based on clinical observation is difficult as symptoms often mimic those of other neurological and rheumatological disorders. Culture of the spirochaete is slow 
and ineffective, and serodiagnosis is problematic, giving both false positives and false negatives.

Considering the success of antibiotic treatment following correct diagnosis, and the severity of untreated cases, it is highly desirable that early and accurate detection of the spirochaete be achieved on a routine basis. PCR has been used successfully to detect $B$. burgdorferi in both cerebrospinal and synovial fluids. Using this approach, we have screened blood samples sent to Ninewells Hospital for routine screening of Lyme disease. The primers selected were used to amplify specific DNA regions of the $B$. burgdorferi outer surface protein B (OspB) located on its 49$\mathrm{kb}$ linear plasmid. This set of primers has been shown to discriminate North American or European isolates of $B$. burgdorferi from related bacterial species, thus providing an effective screening tool for our study.

INCREASED DETECTION OF CHLAMYDIA TRACHOMATIS FROM MALES WITH NONGONOCOCCAL URETHRITIS BY THE POLYMERASE CHAIN REACTION

\section{K. M. Oxley, A. Eley, R. Patel* and G. Kudesia $†$}

Department of Experimental and Clinical Microbiology, University of Sheffield Medical School, Department of GenitoUrinary Medicine*, Royal Hallamshire Hospital, Sheffield, and tThe Public Health Laboratory, Northern General Hospital, Sheffield

The acceptance of the polymerase chain reaction (PCR) as a routine procedure, when compared with established detection methods, will depend to some extent on the widespread use of the technique in conjunction with the clinical follow-up of discrepant results.

The detection of Chlamydia trachomatis from patients with non-gonococcal urethritis (NGU) in Sheffield has been approximately $35-40 \%$, although a higher prevalence is suspected clinically and epidemiologically. Use of PCR, therefore, offered the potential to increase the detection of C. trachomatis, and allowed us to investigate these cases. A total of 95 urethral specimens from males with NGU was tested for $C$. trachomatis by enzyme immunoassay (EIANovo Nordisk ${ }^{\mathrm{TM}}$ ) and PCR at different laboratories in a blind trial. Of 32 specimens positive by EIA, two were found to be negative by PCR; however, PCR amplified chlamydia DNA in a further 16 samples. For those patients who were positive for $C$. trachomatis by PCR only, 14 had symptoms as well as signs of infection, with 10 displaying large numbers of pus cells on microscopy. In this group, contact history data was unavailable in the majority of cases where casual partners could not be traced. However, four patients were found to have chlamydia-positive partners.

THE SELECTION OF LISTERIA MONOCYTOGENES SPECIFIC DNA PROBES USING SUBTRACTIVE HYBRIDISATION

C. M. Gooding, M. R. Knox, S. D. Garrett, H. A. Powell, B. M. Lund and R. A. McKee

AFRC Institute of Food Research, Norwich Research Park, Colney, Norwich NR4 7UA

Rapid detection of Listeria monocytogenes by nucleic acid probes or genic amplification (PCR) requires the isolation and identification of nucleic acid sequences unique to that organism. The technique of subtractive hybridisation selectively removes DNA sequences common to the target and competing organisms, leaving those sequences unique to the target organism. The selection of the DNA is based on the specificity of the selected DNA for the target organism and not on the function encoded by that DNA.

We have used subtraction to remove DNA sequences common to $L$. monocytogenes and the closely related species $L$. innocua. The resulting $L$. monocytogenes-enriched DNA was then used to screen a genomic library of this organism, and approximately 40 fragments were selected for further characteristation. A number of these DNA fragments are $L$. monocytogenes specific and thus have the potential to be used as probes. DNA sequencing of fragments has to date shown no homologies to published sequences.

The technique of subtractive hybridisation has proved very effective in generating DNA probes which are specific for $L$. monocytogenes. This generic technology could be applied to the generation of DNA probes for other pathogenic micro-organisms.

TYPING OF ENTEROCOCCUS FAECALIS FROM FAECES AND URINE

Esther Simpson, Brigid Duke and Lucinda Hall

London Hospital Medical College, Turner Street, Whitechapel, London E1

Enterococcus faecalis is a common cause of urinary tract infection (UTI) in hospitals and is also a common member of the normal faecal fiora. An investigation was carried out into endogenous infection as a cause of $E$. faecalis UTI.

The first stage was to identify the number of $E$. faecalis strains carried by normal individuals. Up to 12 such organisms from each of 26 faecal samples were typed by antibiogram and biochemical methods. Sets of organisms from five individuals were also typed by a DNA restriction method.

The results showed that $21(80.8 \%)$ of 26 people carried only one $E$. faecalis type. Four $(15.4 \%)$ carried two and only one $(3.8 \%)$ had three strains. DNA results were always consistent with antibiogram and biochemistry.

The second stage is to investigate if one of the strains present in the faecal flora is the same as that causing infection in cases of $E$. faecalis UTI. In the one case so far investigated, the organisms from the urine and faeces had identical antibiograms and biochemistry. DNA studies will be used to confirm the identity of these strains.

\section{A STANDARD PROTOCOL FOR ANALYSIS OF ELECTROPHORETIC BAND PATTERNS}

\section{Peiris}

Preston Public Health Laboratory, Royal Preston Hospital, Preston PR2 4HG

Further uses for electrophoretic techniques continue to be found in microbiology despite well-recognised difficulties concerning reproducibility and pattern recognition. A formula has been devised to translate band position into a figure representing percentage migration within a userdefined segment (defined by extrapolation of marker bands across the entire width of a gel). Results generated by using this formula on samples run on more than one gel may then be treated as if they had been run on a single "virtual gel" thereby improving both intra- and inter-gel reproducibility.

The formula states:

$R_{m} S^{x}=\left(D_{S B}{ }^{x}-D_{M B}{ }^{s}\right) /\left(D_{M B}{ }^{e}-D_{M B}{ }^{s}\right) \times 100$

Where-

$\mathrm{R}_{\mathrm{m}} \mathrm{SB}^{\mathrm{x}}$ is the relative migration of a band $\mathrm{x}$ produced by a sample within a particular segment (expressed as a percentage), $D_{S B}{ }^{x}$ is the distance travelled by band $x, D_{M B}{ }^{s}$ is the distance travelled by the marker band defining the start of 
the segment (i.e., nearer the origin) and $\mathrm{D}_{\mathrm{MB}}{ }^{\mathrm{e}}$ is the distance travelled by the marker band defining the end of the segment (i.e., further from the origin), all distances being measured from the baseline (a line representing the position of the sample well).

SERODIAGNOSIS OF APPARENTLY CULTURENEGATIVE ENDOCARDITIS

\section{Clark and J. P. Burnie}

Division of Bacteriology, Department of Pathological Sciences, University of Manchester Medical School, Oxford Road, Manchester M13 9PT

Serum from 72 cases of apparently culture-negative endocarditis were immunoblotted against pressates of two enterococcal (Enterococcus faecalis, E. faecium), six streptococcal (Streptococcus bovis, $S$. sanguis, $S$. mitis, S. mutans, $S$. agalactiae, $S$. pneumoniae) species and Candida albicans. Immunoblotting identified the aetiological pathogen in $47 \%$ of cases; in $43 \%$ this was species specific. In $32 \%$ of cases with apparently culture-negative endocarditis where there was a negative serodiagnosis, a different clinical outcome was found. In only $21 \%$ of cases did a clinical diagnosis of culture-negative endocarditis remain, with the pathogen being completely evasive in only $4 \%$.

The use of immunoblotting greatly improved the clinical diagnosis of culture-negative endocarditis, identifying the causative organism in $47 \%$, of which $91 \%$ were streptococcal/ enterococcal in origin.

DETECTION OF CHLAMYDIA TRACHOMATIS IN PATIENTS WITH ACUTE EPIDIDYMITIS

\section{K. M. Oxley, A. Eley and C. W. Potter}

Department of Experimental and Clinical Microbiology, University of Sheffield Medical School, Beech Hill Road, Sheffield SIO $2 R X$

Infection with Chlamydia trachomatis is the most frequent cause of acute epididymitis in sexually active men under 45 years of age. However, due to the relative insensitivity of laboratory methods the detection rate does not confirm the importance of this organism when assessed by serological techniques. Furthermore, it is known that prostatic fluid is toxic to McCoy cells and is unsuitable for testing by tissue culture.

In an initial study, 11 patients presenting with acute epididymitis were examined for $C$. trachomatis by growth in tissue culture and antigen detection (EIA), and for other micro-organisms by conventional microbiological tests. In addition, the polymerase chain reaction (PCR) was applied to detect any residual $C$. trachomatis DNA in urethral and expressed prostatic secretions. Conventional tissue culture and EIA were able to identify $C$. trachomatis infection in four patients; $P C R$ confirmed these infections and detected C. trachomatis in a further five cases. Gardnerella vaginalis was isolated from one patient in the absence of evidence in infection by any other organism, and in one patient no organisms were isolated.

These results confirm the diagnostic value of the PCR and the importance of $C$. trachomatis in epididymitis.

\section{ANALYSES OF SKIN SURFACE LIPID IN THREE \\ MICROBIAL SKIN DISEASES}

\section{S. D. Patel and W. C. Noble}

Department of Microbial Diseases, Institute of Dermatology, United Medical and Dental Schools, St Thomas' Hospital, London SE1 $7 E H$
The total casual skin surface lipid, the free fatty acids and the fatty acids of triglycerides in three groups of patients have been analysed by thin-layer and gas-chromatography. Two groups of patients had diseases associated with lipophilic organisms; acne vulgaris is associated with Propionibacterium acnes whilst pityriasis versicolor and seborrhoeic dermatitis are associated with Malassezia (Pityrosporum) spp. The remaining patients had atopic dermatitis in which the skin is almost invariably colonised by Staphylococcus aureus. Discriminant analysis showed that all three groups of patients could be separated on the basis of skin lipid composition suggesting that lipid may be involved in predisposition to certain diseases. Differences in skin lipid pre- and post-treatment may reflect the changes in microbial flora during therapy or more directly reflect host changes in the skin ecosystem. Manipulation of skin lipid composition might prove an effective way of controlling some disease, perhaps by its effect on the skin flora.

\section{AEROBIC NON-LIPOPHILIC CORYNEFORMS FROM HUMAN FEET}

\section{R. M. Anthony, D. G. Pitcher* and W. C. Noble}

Department of Microbial Diseases, Institute of Dermatology, United Medical and Dental Schools, St Thomas' Hospital, London SEI 7EH and *National Collection of Type Cultures, Central Public Health Laboratory, Colindale, London NW9 $5 H T$.

Aerobic, non-lipophilic coryneform bacteria from the toe webs of coal-miners with tinea pedis have been studied by analysis of cell-wall sugars, lipids, and amino acids and by phenotype tests using the API CORYNE kit. Many of the isolates were assignable to the genus Brevibacterium, probably $\boldsymbol{B}$. epidermidis, none was assignable to Dermabacter. Two apparently new taxa were recovered. One is probably close to Brevibacterium in that isolates may produce methane thiol and degrade tyrosine though not xanthine but they do not possess meso-DAP in the cell wall and colonies are yellow pigmented. The other is orange pigmented, does not produce methane thiol, degrade tyrosine or xanthine or possess mesoDAP. It also differs substantially in its lipid composition and is sensitive to mupirocin, a characteristic not shared by other coryneform genera from human skin. This brings to four the taxa of aerobic, non-lipophilic coryneform from human skin.

A TAXONOMIC STUdY FOR THE GENUS PREVOTELLA

R. Yousefi-Mashouf, A. Eley. L. Goodwin, J. Magee and B. I. Duerden*

Department of Experimental and Clinical Microbiology, University of Sheffield Medical School, Sheffield S10 2RX and *Department of Medical Microbiology and Public Health Laboratory, University of Wales College of Medicine, Heath Park, Cardiff CF 4 4XN

Gram-negative anaerobic bacilli, previously known as the melaninogenicus-oralis group of Bacteroides, have recently been assigned to a new genus, Prevotella.

Several approaches were used to characterise 22 reference strains of Prevotella (Bacteroides) spp. and 96 clinical isolates from 21 adult patients with periodontal disease. Strains were examined in tests for: conventional test reaction patterns (CTRPs); fluorescence under UV light; gas-liquid chromatography (GLC); pre-formed enzyme tests; SDS-PAGE and pyrolysis mass spectrometry (PMS).

Species were distinguished by CTRP, GLC and preformed enzyme tests and an identification scheme was designed for non-pigmented and pigmented Prevotella spp. 
Twelve groups (A-L) were obtained for 96 clinical isolates; 63 strains gave results identical with those of reference strains and 26 showed only minor variations. The commonest species were $P$. buccae (42), $P$. veroralis (15) and $P$. oralis (8). PMS and CTRP classifications were compared with a classification based on visual analysis of SDS-PAGE patterns. There was close correlation between CTRP, SDSPAGE and PMS. Clustering membership in the PMS and SDS-PAGE classification was particularly good; both gave a larger number of clusters than the CTRP classification. Furthermore, SDS-PAGE and PMS divided two species into sub-groups: three in $P$. buccae, and five in $P$. veroralis.

RECOGNITION OF MALASSEZIA FURFUR ISOLATES BY PULSE FIELD GEL ELECTROPHORESIS

\section{S. A. Howell and G. Midgley}

Institute of Dermatology, St Thomas' Hospital, London SE1 $7 E H$

The lipophilic yeast Malassezia furfur is a common commensal of post-pubertal individuals which has also been associated with the superficial skin diseases dandruff, seborrhoeic dermatitis and pityriasis versicolor. In recent years, $M$. furfur has also been reported as a cause of fungaemia in neonates receiving intravenous lipid emulsions.

There are no reported methods of strain recognition for $M$. furfur although various morphological groups can be identified by microscopy, SDS-PAGE and serological techniques. Karyotyping by pulsed field gel electrophoresis has successfully differentiated strains of Candida albicans (2) and serotypes of Cryptococcus neoformans (4). This technique was therefore applied to a collection of $M$. furfur isolates obtained from the skin of inpatients and nurses of obstetrics and paediatrics wards and the range of karyotypes was compared. The results demonstrated close agreement with the morphological groups, but little strain variation was observed.

ESTABLISHMENT OF INTERPRETATIVE STANDARD FOR SUSCEPTIBILITY TESTING OF METRONIDAZOLE AGAINST HELICOBACTER PYLORI

H. X. Xia, M. A. Daw, L. English, C. T. Keane and C. A. O'Morain

Department of Clinical Microbiology (TCD), St James's Hospital, and Department of Gastroenterology, Meath/ Adelaide Hospitals, Dublin, Ireland

Susceptibility testing of Helicobacter pylori to metronidazole (MTZ) has an important role in the management of $\boldsymbol{H}$. pylori infection as clinical isolates with a minimum inhibitory concentration (MIC) of $16 \mathrm{mg} / \mathrm{L}$ or more may not respond to therapy. Simpler and more precise methods of susceptibility testing are required for routine use. The aims of this study were (i) to determine the distribution of MIC of clinical isolates of $H$. pylori by a plate dilution method (PDM); and (ii) using the MIC values obtained to establish a breakpoint system by correlating the zone diameters of inhibition given with a 5-mg MTZ-disk diffusion test (DDT). The susceptibilities of 121 clinical isolates were determined by both the PDM and the DDT in duplicate during 3, 4, 5, 6 and 7 days of incubation. Correlation of MICs and zone diameters was calculated by logarithmic regression, and the equation $\mathrm{X} 1 \mathrm{~S} 2+\mathrm{X} 2 \mathrm{~S} 1 /(\mathrm{S} 1+\mathrm{S} 2)$ was used to establish the minimum zone diameter indicating sensitivity of the isolate. The distribution of MICs of MTZ against $H$. pylori exhibited a bimodal distribution among sensitive and resistant isolates. The highest percentage of isolates among the sensitive isolates was those with MIC of $1 \mathrm{mg} / \mathrm{L}$ and among resistant isolates were those with $\mathrm{MIC}$ of $32 \mathrm{mg} / \mathrm{L}$. The best correlation between MICs and zone diameters was obtained after incubation for 4 days $(r=0.9960)$ followed by incubation for 3 days $(r=0.9819)$. Using the above equation, a zone diameter of $12 \mathrm{~mm}$ was found to be the most useful in determining sensitivity. After incubation for 3 days a $3 \%$ false reading for both sensitive and resistant isolates occurred. In conclusion, distribution of MIC of MTZ against $H$. pylori was bimodal. Results from PDM and the DDT showed a good correlation. A zone of inhibition more than $12 \mathrm{~mm}$ with the DDT indicated sensitivity of the isolates.

\section{FAILURE OF ANTIREACTIVATION VACCINES IN A DORMANCY MODEL OF MURINE EXPERIMENTAL TUBERCULOSIS}

\section{Jasvir Dhillon and D. A. Mitchison}

Department of Bacteriology, Royal Postgraduate Medical School, Du Cane Road, London W12 0NN

Since most people in developing countries are infected with tubercle bacilli when young, "antireactivation" vaccines would have a much greater effect than "preventive" vaccines of the BCG type. We described the results with putative antireactivation vaccines in a dormancy model in the mouse. Our BALB/c mice were infected intravenously with Mycobacterium tuberculosis, $\mathrm{H} 37 \mathrm{Rv}$ and the disease allowed to progress for 2 weeks to reach $6.49 \log _{10} \mathrm{cfu} /$ spleen. Treatment was given with isoniazid $20 \mathrm{mg} / \mathrm{kg}$ and pyrazinamide $1000 \mathrm{mg} / \mathrm{kg}$ in the diet for 14 weeks. At the end of treatment, only one spleen from the organs of 20 mice was positive. The mice then received: A, a heat-killed $M$. vaccae vaccine into footpads; $\mathrm{B}$, isoniazid-resistant $\mathrm{BCG}$ divided between three subcutaneous sites, repeated after 2 weeks; or C, saline into footpads. Three months later, the entire spleens and lungs were inoculated into liquid medium to measure the relapse rate to a culturable infection. The proportions of positive cultures from spleens were 32 of 45 in group A, 28 of 45 in B and 39 of 49 in C and from lungs 16 of 45,16 of 45 and 18 of 49 , respectively. The vaccines had no influence on the relapse rate.

\section{THE ROLE OF PCR IN THE DIAGNOSIS OF TUBERCULOSIS}

\section{De Wit, G. Maartens and L. Steyn}

Department of Bacteriology, Royal Postgraduate Medical School, Du Cane Road, London W12 ONN

Recently several large clinical trials have shown that, although PCR is more sensitive than laboratory culture for the detection of Mycobacterium tuberculosis, there may be problems with interpretation of PCR positive, culture negative specimens.

To evaluate the role of PCR more accurately, we compared laboratory culture of pleural fluid with PCR of the pleural fluid. Culture and histology of the pleural biopsy as well as clinical evidence were used to confirm PCR results.

Eighty-four adult patients with pleural effusions were entered into a prospective study. On the basis of the results of conventional detection techniques as well as an evaluation of the clinical data, 53 patients were considered to have active tuberculosis. Analysis of the pleural fluid confirmed a sensitivity for PCR of $81 \%$. The sensitivity of pleural fluid culture, culture of pleural biopsy, and histology of biopsy was $52.8 \%, 69.8 \%$ and $77.3 \%$ respectively. There were, however, seven PCR-positive results within the control group; six of these were in-patients with malignant effusions. We conclude that for the diagnosis of $M$. tuberculosis, PCR is more sensitive than laboratory culture as determined by 
the analysis of pleural fluids. Positive PCR results among patients with malignant effusions may be false positives or the result of latent tuberculous infections.

BCL-2 EXPRESSION IN EPSTEIN-BARR VIRUS (EBV) ASSOCIATED POST-GRAFT B LYMPHOPROLIFERATIVE DISEASE

\section{J. A. Thomas and D. H. Crawford*}

ICRF/RCS Histopathology Unit, Imperial Cancer Research Fund, London WC2A $3 P N$ and *Department of Clinical Sciences, London School of Hygiene and Tropical Medicine, London WCIE 7 HT

Over-expression of the B cell lymphoma-2 gene protein (bcl-2) appears to provide a selective growth advantage to $B$ cells in vitro and protect them from programmed cell death/ apoptosis. Recent DNA transfection studies have shown that enhanced survival of EBV-infected human B cells in vitro is conferred by the EBV latency-associated membrane protein, LMP, through LMP-induced upregulation of bcl-2.

This immunocytochemical study examined bcl-2 expression in EBV-related post-graft B cell tumours in which most of the tumour cells displayed the full repertoire of latent viral antigens usually associated with EBV-induced immortalisation of normal $B$ cells in vitro. The latent viral gene products include EB nuclear antigens (EBNAs) $1-6$ and LMP, of which EBNA2 and LMP appear to have essential roles in maintaining continued cell proliferation. Positive bcl-2 staining was found in about $50 \%$ of tumours. Double labelling studies revealed selective bcl-2+/EBNA2 + and rcl-2 + LMP + expression on only a proportion of neoplastic cells. This phenotypic heterogeneity suggests that EBNA2 as well as LMP may serve in bcl-2 regulation and that bcl-2 prolonged cell survival may contribute to the outgrowth of neoplastic B cells in some but not all cases of post-graft B lymphoproliferative disease.

B CELL LEUKAEMIA/LYMPHOMA (BCL)-2 GENE EXPRESSION IN NASOPHARYNGEAL CARCINOMA AND NORMAL ORONASOPHARYNGEAL EPITHELIUM

Lu Qi Long and J. A. Thomas

ICRF/RCS Histopathology Unit, Imperial Cancer Research Fund, 35-43 Lincolns Inn Fields, London WC2A 3PN

$\mathrm{Bcl}-2$ gene expression is associated with inhibition of programmed cell death in $B$ cells. In recent DNA transfection studies, the prolonged survival of Epstein Barr virus (EBV) infected $B$ cells relates to expression of the latent viral gene product, latent membrane protein (LMP)-1 and LMP-1 induces upregulation of bcl-2. LMP-1 also has tumourigenic properties, and in EBV associated undifferentiated nasopharyngeal carcinoma (UNPC), LMP-1 forms part of the restricted latent viral antigen profile displayed by the tumour cells.

This study examined the relationship between bcl-2 and LMP-1 expression in frozen and routinely processed samples of EBV-associated uNPC. Immunocytochemical demonstration of bcl-2 + tumour cells in $12(86 \%)$ of 14 samples of uNPC was confirmed by immunoblotting in six cases. Since bcl-2 expression in uNPC has not been reported previously, further studies showed that bcl-2 was present in $5(62 \%)$ of eight histological variants of NPC which had no evidence of $\mathrm{EBV}$ involvement, and was constitutively expressed in some basal cells of normal (EBV - ) oral and nasopharyngeal squamous epithelium. By contrast, bcl-2 was not expressed in oral hairy leukoplakia which indicates the presence of replicating EBV. These findings indicate that bcl-2 is not exclusively dependent on EBV latent gene expression in NPC and may be involved in growth regulation of some normal squamous epithelium.

EPSTEIN BARR VIRUS (EBV) ASSOCIATED T CELL LYMPHOMA IN AIDS

\section{J. A. Thomas, F. Cotter*, A. Hanby and P. Morgan $\dagger$}

ICRF/RCS Histopathology Unit, Imperial Cancer Research Fund, 35-43 Lincolns Inn Fields, London WC2A 3PN, *Medical Oncology Unit, St Bartholomew's Hospital, London ECIA $7 B E$ and +Department of Oral Medicine and Pathology, Guy's Hospital, London SE1 9RT

The strictly B lympho-epitheliotropic nature of Epstein Barr virus (EBV) has been challenged by recent evidence that normal $T$ cells and thymocytes support short-term EBV infection in vitro. Furthermore, EBV involvement has been clinically documented in small numbers of patients with $\mathrm{T}$ cell disorders ranging from reactive hyperplasia to high grade malignant lymphoma.

Here we report oral mucosal-associated $T$ cell lymphoma in three HIV-seropositive individuals in whom the tumour cells were found to contain EBV DNA and express latent viral gene products. The $T$ cell nature of the lesions was established by immunophenotyping, and by gene re-arrangement studies with the polymerase chain reaction. AIDSrelated $\mathrm{T}$ cell lymphoma may be a new clinical entity and EBV involvement in these lesions has not been described previously. An important implication of these findings is that severe immunosuppression induced by HIV (and possibly other as yet undefined causes) may increase the range of host cells susceptible to EBV infection and sustain neoplastic transformation in these cells.

\section{ORAL PRESENTATIONS}

THE RAPID DETECTION AND TYPING OF NEISSERIA MENINGITIDIS BY POLYMERASE CHAIN REACTION

A. F. Maggs, P. E. Carter*, T. H. Pennington* and H. M. Dick

Department of Medical Microbiology, University of Dundee Medical School, Ninewells Hospital, Dundee and * Department of Medical Microbiology, University of Aberdeen Medical School, Foresterhill, Aberdeen

Neisseria meningitidis remains one of the most common causes of bacterial meningitis in the UK. Whilst its diagnosis is usually straightforward by examination of cerebrospinal fluid (CSF), this can be a problem when the number of organisms are low, or the infection has been partially treated by antibiotics. Due to its sensitivity and the ability to detect non-viable bacteria, we have investigated the use of the polymerase chain reaction (PCR) for the detection of $N$. meningitidis.

Over 100 isolates have been examined by PCR with primers designed from the outer membrane protein 1 (OMP1) sequence, using dilute suspensions of bacteria within sterile CSF, or CSF taken from patients with bacterial 
meningitis. As well as NCTC meningococcal and nonmeningococcal controls, clinical isolates included a number of serogroups and serotypes from a wide range of geographical sources.

Bacteria could be detected by PCR in samples of CSF from clinical cases of meningcoccal meningitis. Overall, a variety of patterns was seen following PCR, both with respect to slight variation in the size of the amplified segment and more obvious variation in restriction endonuclease (RE) profile. In some cases serogroups could be distinguished by RE digest pattern, often with further subdivision possible, even though OMP1 is not responsible for serogroup or serotype specificity. PCR examination of samples of CSF represents a promising tool for the rapid diagnosis of meningococcal meningitis.

\section{PCR IN THE INVESTIGATION OF 4-QUINOLONE RESISTANCE}

\section{E. G. M. Power, I. Phillips and L. M. Fisher*}

Department of Microbiology, UMDS, St Thomas' Hospital, Lambeth Palace Road, London SE1 $7 E H$ and ${ }^{*}$ Department of Cellular and Molecular Sciences, St George's Hospital Medical School, Cranmer Terrace, London SW17 ORE

Resistance to the 4-quinolone antibiotics is a gradually increasing phenomenon. In clinical isolates the cause of this resistance is primarily due to a mutation in the gyrA gene, which codes for GyrA subunit of DNA gyrase, the enzyme target of the 4-quinolones. In Escherichia coli and staphylococci, a single coding change towards the $5^{\prime}$ end of the gyr $A$ gene results in a quinolone-resistant gyrase enzyme. This change, due to one base substitution, can be detected at the molecular level because it removes a HinfI restriction site. We have amplified the relevant region from the chromosomal DNA of strains of E. coli and Staphylococcus epidermidis by PCR and shown that quinolone-resistant strains have altered restriction fragment profiles compared to sensitive strains.

Sequencing of the PCR products showed a $C$ to $T$ transition resulting in an amino acid change from serine to leucine at position 83 in $E$. coli and position 84 in $S$. epidermidis.

These techniques are excellent tools in determining the molecular basis of GyrA-mediated resistance to 4-quinolones in gram-positive and gram-negative bacteria.

\section{SUSCEPTIBILITY TO CIPROFLOXACIN IN NEISSERIA GONORRHOEAE}

C. A. Ison, N. S. Roope, P. J. Woodford and C. S. F. Easmon

Department of Medical Microbiology, St Mary's Hospital Medical School, Norfolk Place, Paddington, London W2 IPG

Ciprofloxacin is now recommended as a first line therapy for gonorrhoea. However, there is little information regarding the relationship between minimum inhibitory concentration (MIC), treatment failure and dosage. To monitor the susceptibility of Neisseria gonorrhoeae to ciprofloxacin and to identify potentially resistant isolates we have used a breakpoint agar dilution method. Media containing ciprofloxacin at $0.008,0.03$ and $0.12 \mathrm{mg} / \mathrm{L}$ were used. To date we have tested 1163 consecutive isolates of $N$. gonorrhoeae from patients attending St Mary's Hospital, London and have found the majority, $1101(94.6 \%)$, to be sensitive to $\leqslant 0.008 \mathrm{mg} / \mathrm{L}$. Of the remainder, $59(5.1 \%)$ had a MIC of $0.015-0.03 \mathrm{mg} / \mathrm{L}$ and three $(0.3 \%)$ had a MIC of $>0.03 \mathrm{mg} /$ $\mathrm{L}$. These three isolates had MICs of $0.12 \mathrm{mg} / \mathrm{L}$ (two strains) and $0.5 \mathrm{mg} / \mathrm{L}$ to ciprofloxacin and of $256 \mathrm{mg} / \mathrm{L}$ to nalidixic acid.
In-vitro spontaneous mutation experiments of clinical isolates to ciprofloxacin resistance have shown the rate to be between $10^{-7}$ and $10^{-9}$. Two classes of mutants were obtained - those exhibiting 2-4-fold increase to ciprofloxacin with little or no concomitant increase to nalidixic acid and those showing 64-256-fold increase to ciprofloxacin with associated 128 -fold increases to nalidixic acid. We have experienced no clinical failures during the last 2 years with a $500 \mathrm{mg}$ stat dose for gonorrhoea but would recommend caution in the use of low therapeutic doses to prevent selection of these mutants in vivo.

THE ACTIVITY OF CIPROFLOXACIN ALONE, AND OF CIPROFLOXACIN WITH RIFAMPICIN AGAINST MYCOBACTERIUM TUBERCULOSIS

\section{G. Cormican and J. Flynn}

Department of Medical Microbiology, University College Hospital, Galway, Ireland

The in-vitro susceptibility to ciprofloxacin of Mycobacterium tuberculosis has been studied by a number of methods. Using the BACTEC radiometric growth detection system, we have demonstrated that inoculum size is an important determinant of the apparent level of resistance as determined by this system. Drug resistance is not entirely masked, however, even with an inoculum substantially smaller than would normally be used.

Twenty-five isolates of $M$. tuberculosis complex (including five resistant to more than one first line agent) were studied. Eleven isolates were further studied by subculture from drug-containing to drug-free vials after incubation for 7 days. Twenty-four isolates were inhibited by ciprofloxacin at a concentration of $1 \mathrm{mg} / \mathrm{L}$, one isolate was inhibited at a concentration of $2 \mathrm{mg} / \mathrm{L}$. All five isolates resistant to the primary antituberculous agents were sensitive to ciprofloxacin at the level of $1 \mathrm{mg} / \mathrm{L}$. From all 11 isolates subcultured after incubation for 7 days in ciprofloxacin-containing vials, mycobacteria were recovered.

In view of the reported antagonism of rifampicin and ofloxacin for $\boldsymbol{M}$. fortuitum, the combination of rifampicin and ciprofloxacin for $M$. tuberculosis was studied. Antagonism was not detected. Ciprofloxacin has substantial activity against organisms of the $M$. tuberculosis complex. However, further study of the effect of combinations of ciprofloxacin with other agents together with clinical studies are required to clarify its role.

MEDIA EFFECTS ON THE SUSCEPTIBILITY OF $X$ ANTHOMONAS MALTOPHILIA TO $\beta$-LACTAM ANTIBIOTICS

\section{M. Livermore, G. Bonfiglio and M. Akova}

Department of Medical Microbiology, The London Hospital Medical College, Turner Street, London E1 2AD

Xanthomonas maltophilia is an opportunist pathogen in seriously ill patients and is resistant to many antibiotics, including $\beta$-lactams. It appears more resistant to many penicillins and cephalosporins on Mueller Hinton (MH) agar than on Diagnostic Sensitivity Test or IsoSensitest (IST) agars. We showed, additionally, that its susceptibility varied according to the dilution at which these media were prepared. MIC and disk tests were performed on solidified MH and IST media prepared at $0 \cdot 1,0 \cdot 3,1$ and $3 \times$ the nutrient concentrations recommended by the manufacturer, but with a constant agar concentration; nine of $10 X$. maltophilia strains showed increased susceptibility to meropenem, cefotaxime, piperacillin, cefoperazone and latamoxef as the nutrient concentrations of the media were 
increased. A single NCTC strain (10257) showed the opposite behaviour on MHA and behaved inconsistently on ISTA. Medium-dependent susceptibility was noted in laboratory mutants which constitutively hyperproduced, or were deficient for, the two chromosomal $\beta$-lactamases which are normally inducible in $X$. maltophilia. This observation belies the possibility that the medium effect could relate to the efficiency of $\beta$-lactamase induction. Altered permeability, therefore, seems a likely cause of the phenomenon, and we noted that growth in richer media led to the induction of additional outer membrane proteins with mol. wts of 22 $25 \mathrm{kDa}$ in $X$. maltophilia. These may affect antibiotic uptake, but this hypothesis remains to be tested. Irrespective of their precise basis, these medium effects suggest that clinical laboratory susceptibility results for $X$. maltophilia should be interpreted with the utmost scepticism.

PATHOGENICITY OF ANTIMICROBIAL MULTIRESISTANT ESCHERICHIA COLI ISOLATED FROM URINARY TRACT INFECTION

P. A Riley and I. Phillips

Department of Microbiology, UMDS, St Thomas's Campus, London SE1 $7 E H$

During the period August 1989 to July 1990,94 isolates of Escherichia coli resistant to amoxycillin, chloramphenicol, streptomycin, sulphonamides, tetracycline and trimethoprim were cultured from specimens of urine submitted for routine culture at St Thomas' Hospital from patients with urinary tract infection.

Clinical information was obtained from 64 patients enabling the infection to be classified as significant (upper tract infection and cystitis) or symptomless colonisation. Data were also obtained on underlying conditions predisposing to urinary tract infection and the patients were classified as compromised or uncompromised; $44(69 \%)$ had significant infection and $20(31 \%)$ had symptomless colonisation; 28 $(44 \%)$ patients had underlying conditions predisposing to infection and $36(56 \%)$ were uncompromised.

These results indicate that antimicrobial multi-resistant strains are as likely to infect an uncompromised patient as a compromised patient, and once established more likely to cause a significant infection than symptomless colonisation. These findings are evidence against the widely held belief that antimicrobial multi-resistant organisms have little or no pathogenic potential.

\section{CYTOCHEMICAL DEMONSTRATION OF BACTERIAL ENZYME ACTIVITY: A NEW APPROACH TO RAPID PRESUMPTIVE IDENTIFICATION}

\section{R. Barer, D. R. Walker, P. M. Marsh and S. M. Thom}

Department of Microbiology, The Medical School, Framlington Place, Newcastle upon Tyne NE2 $4 \mathrm{HH}$

Light microscopic cytochemical techniques offer a direct means of rapidly assigning specific activities to individual microbial cells without an intervening period of in-vitro culture. They should, therefore, allow determination of identity and activity at a stage in processing when organisms present in a clinical specimen are detectable by microscopy.

Establishment of a procedure for immobilising viable bacteria on optical quality glass has enabled us to develop cytochemical techniques which demonstrate $\beta$-galactosidase and cytochrome oxidase in unfixed bacterial cells. This report documented our first steps in examining the potential clinical application of these procedures. $\beta$-Galactosidase demonstration was achieved with indoxyl $(100 \mathrm{~min})$, indoxyltetrazolium (20 min), and fluorescein digalactoside (FDG) ( $8 \mathrm{~min}$ ) based techniques. A 10-min diaminobenzidine (DAB) technique demonstrated oxidase activity. FDG and DAB techniques were applied to over 40 recent blood culture isolates of gram-negative bacilli. No discrepancies from the conventional macroscopic lactose fermentation and oxidase tests were observed. Preliminary studies on preparations made directly from blood cultures indicate that the presence of blood-cell debris does not affect the reliability of the FDG and DAB tests.

Cytochemical tests offer a promising new approach to the rapid provision of information relevant to the management of acute infections.

\section{SYMPOSIUM: MICROBIOLOGY AND THE MOUTH \\ (in collaboration with the Oral Microbiology and Immunology Group) \\ Chairman: I. Phillips}

\section{ORAL MANIFESTATIONS OF HIV INFECTION}

\section{S. J. Challacombe}

Oral AIDS Research Centre, Department of Oral Medicine and Pathology, UMDS, Guy's Hospital, London E1 9RT

Oral manifestations of HIV infection are not only an integral part of the diagnosis and management of HIV infection, they are frequently the earliest signs of HIV infection and conversion to the full AIDS syndrome. To date, over 40 oral signs of HIV infection have been reported including eight types of fungal infection, 11 types of bacterial infection, nine types of viral infection and various lesions not of secondary infective origin. Recently these lesions have been classified into three groups: I, those strongly associated with HIV infection; II, those commonly associated with HIV infection; and III, those possibly associated with HIV infection. Category I contains lesions including hairy leukoplakia and pseudo-membranous candidiasis which are almost pathognemonic of HIV infection as well as necrotising ulcerative gingivitis, HIV-associated periodontal disease and HIV gingivitis, oral Kaposi's sarcoma and non-Hodgkin's lymphoma. Up to $40 \%$ of those with HIV and $80 \%$ of those with AIDS may present with candida infection. Hairy leukoplakia can be found in up to $14 \%$ of HIV-positive and may be a prognostic marker for early conversion to AIDS. A similar range and prevalence of oral lesions has been reported with HIV-2 infection.

Recognition of the oral manifestations of HIV infection is an essential part of management. The oral cavity provides an accessible mucosal site not only for the diagnosis but also for investigation of the effect of HIV infection on mucosal immunity.

\section{ORAL VIRAL INFECTIONS}

J. Bagg

Department of Oral Medicine and Pathology, Glasgow Dental Hospital and School, 378 Sauchiehall Street, Glasgow G2 3JZ

Viruses may cause disease by establishing acute infections, persistent infections (including those exhibiting latent or oncogenic potential) and by stimulating autoimmunity. All 
are relevant to oral disease. Acute viral infections of the mouth include herpetic gingivostomatitis, herpangina and hand, foot and mouth disease. Other systemic viral infections, e.g., infectious mononucleosis, may also have oral manifestations. Latent infections are epitomised by herpes viruses, and reactivation of both herpes simplex virus (HSV) and varicella zoster virus may affect the territory of the trigeminal nerve. Asymptomatic shedding of herpes viruses into saliva requires further investigation. Epstein-Barr virus (EBV) is causally linked with both Burkitt's lymphoma and nasopharyngeal carcinoma, and is consistently associated with oral hairy leukoplakia. Some human papilloma viruses are strongly implicated in the aetiology of oral squamous cell papillomas. Oral diseases with an immune pathogenesis may be triggered by viruses. Latent EBV is present in salivary glands and the vigorous immune response in Sjogrens syndrome may result from breakdown of the mechanism for viral persistence. Circumstantial evidence suggests a potential role for HSV in the aetiology of aphthous ulceration and Behcet's disease, possibly by impairing $\mathrm{T}$ cell immunoregulation. In summary, viruses may be responsible for many oral diseases. The scope of their involvement is likely to widen with application of molecular biological techniques.

\section{ACTIVE AND PASSIVE IMMUNISATION IN THE PREVENTION OF DENTAL CARIES}

\section{T. Lehner, J. Ma, L. Bergmeier and C. Kelly}

Department of Immunology, United Medical and Dental Schools of Guy's and St Thomas' Hospitals, London

Streptococcus mutans is the principal organism in the development of dental caries. A streptococcal antigen (SAI/ II) with a $M_{r}$ of $185 \mathrm{kDa}$ and a cross-reactive $S A$ with a $\mathrm{M}_{\mathrm{r}}$ of 3800 have been extensively investigated. They are expressed on the cell surface of $S$. mutans and the $185^{-\mathrm{kDa}}$ SA may function as an adhesin and has been cloned and sequenced. Both, high and low $M_{r}$ SA elicit natural serum and salivary antibodies and $T$ cell responses in man. The antigens and a synthetic peptide of 17 residues are immunogenic in non-human primates in which active immunisation elicits a protective immune response against colonisation with $S$. mutans and the development of dental caries.

Passive immunisation by monoclonal antibodies (MAb) to SAI/II decreases colonisation of teeth by $S$. mutans and the development of dental caries. Passive immunisation studies were then pursued in human subjects. Topical application of MAb to SAI/II in man prevented colonisation of both artificially implanted exogenous strains of $S$. mutans, as well as natural recolonisation by indigenous $S$. mutans. The properties of the protective MAb were then investigated and the epitope specificity within the SAI/II molecule was found to be essential but not the immunoglobulin class. The requirement for complement activating and the phagocyte binding sites of the Fc fragment of MAb was not essential, as the $F(a b)_{2}$ fragment of the MAb was as protective as the intact IgG, but the $\mathrm{Fab}$ fragment failed to prevent recolonisation of $S$. mutans in the human mouth. Prevention of recolonisation was specifically restricted to $S$. mutans, as the proportion of other organisms such as $S$. sanguis failed to show a significant change. The suprising feature of these experiments was that protection against recolonisation of $S$. mutans lasted up to 2 years, although MAb was applied for only 3 weeks and functional MAb was detected on the teeth only up to 3 days following application of the MAb. The long-term protection could, therefore, not be accounted for by a persistence of MAb on the teeth but may be due to a shift in the balance of the oral flora which replaced the ecological niche occupied by $S$. mutans by another plaque organism.

\section{CROSS-INFECTION IN DENTISTRY}

\section{A. Clark}

Department of Experimental and Clinical Microbiology, University of Sheffield Medical School, Sheffield S1O 2RX

The medical microbiologist must be aware of the problems of cross-infection on dentistry in order to provide dentists with accurate information and realistic advice. Dentistry presents many potential cross-infection problems that are compounded by a rapid patient turn-over rate. The "high risk" patient is the main potential source of infection, principally for the dentist and surgery assistant but other personnel must also be considered. Significantly, dental personnel may also be a source of infection. The most important potential micro-organisms are Hepatitis $\mathrm{B}, \mathrm{Hu}$ man Immunodeficiency Virus (HIV), Herpes simplex, antibiotic multi-resistant staphylococci and tuberculosis. "At risk" patients require special consideration and include some of the "high risk" groups and also the immunocompromised patient such as those with acute leukaemia who are especially vulnerable to a wide range of micro-organisms such as Pseudomonas spp., the common cold and influenza viruses. Dental units are frequently colonised by Pseudomonas spp. The prevention of cross-infection through dentistry is about awareness and common sense coupled with a sound microbiological knowledge of the nature of micro-organisms. In particular, correct instrument sterilisation procedures and routine disinfection of potentially contaminated areas must be strictly adhered to; hands and eyes must be protected; relevant immunisations must be kept up-to-date; and contaminated waste correctly disposed of.

\section{PATHOGENESIS OF BACTERIAL ENDOCARDITIS}

\section{W. I. Douglas}

Department of Oral Pathology, School of Clinical Dentistry, University of Sheffield, Sheffield S10 2TA

Bacterial endocarditis remains an important cause of morbidity and mortality. It is characterised by the production of thrombotic vegetations at sites of endocardial damage, which become colonised by bacteria. Although many organisms can cause endocarditis, the oral streptococci are the most common, and among these Streptococcus sanguis and $S$. oralis predominate. The pathogenic mechanisms by which organisms give rise to endocarditis are poorly understood but dextran production, presence of lipoteichoic acid, interaction with fibronectin and aggregation of platelets have all been suggested as important in $S$. sanguis-mediated endocarditis. There is some controversy as to which of the above is the most important factor but some work implicates surface protein as responsible for bacterial adherence to vegetations. Also, the ability of $S$. sanguis to interact directly with platelets would explain its predilection for thrombotic vegetations and the majority of strains of this organisms cause platelets to aggregate. Recently, a $65 \mathrm{kDa}$ protein has been suggested as the ligand responsible for platelet aggregation and we have evidence that a platelet-membrane glycoprotein (Ib) is the target receptor. 


\section{ORAL PRESENTATIONS}

CYTOTOXIC NECROTISING FACTOR (CNF) PRODUCING ESCHERICHIACOLIISOLATED FROM ANIMALS

\section{Wray and P. J. Carroll}

Central Veterinary Laboratory, New Haw, Weybridge, Surrey KT15 $3 N B$

Cytoxic necrotising factor (CNF) was first described in Escherichia coli isolated from infants. This cytotoxin causes mutlinucleation and giant cell formation in Vero cell monolayers. Since 1990 , all $E$. coli isolates received at our laboratory have been examined for their toxicity to Vero cells. Of the 235 bovine isolations, $8 \%$ produced $C N F$, the commonest $\mathrm{O}$ groups being $\mathrm{O} 26, \mathrm{O} 75, \mathrm{O} 76$ and $\mathrm{O} 88$. Of the 705 porcine isolations, $6 \%$ produced CNF, the commonest $\mathrm{O}$ groups being $\mathrm{O6}, \mathrm{O} 32, \mathrm{O} 75$ and $\mathrm{O} 88$. In addition $\mathrm{CNF}+$ $E$. coli have been isolated from sheep and deer. The CNF+ isolates were associated with disease conditions ranging from diarrhoea to acute haemorrhagic enteritis and, in some cases, septicaemia. Some of the cattle strains produced a mannose-resistant adhesin and others were associated with the fimbrial antigen F6 (987P).

EXPERIMENTAL INFECTION OF PIGLETS WITH CYTOTOXIC NECROTISING FACTOR (CNF)PRODUCING ESCHERICHIA COLI

C. Wray, D. W. T. Piercy and P. J. Carroll

Central Veterinary Laboratory, New Haw, Weybridge, Surrey KT15 $3 N B$

Two litters of 2-3-day-old piglets were infected orally with CNF-producing Escherichia coli. Of the six piglets in the litter challenged with $10^{9} E$. coli 088 , two died the day after challenge and three developed diarrhoea. Large numbers of the challenge strain were isolated from the viscera of those dying of septicaemia, whereas the number of organisms in the tissues of diarrhoeic piglets was much smaller. The pathological changes in the major organs were consistent with toxaemia and the changes included hepatitis, glomerulonephrosis and limited cerebrocortical necrosis. An exudative broncho-interstitial pneumonia occurred suggesting that enteroinvasion may have occurred.

The second litter was infected orally with $10^{10} E$. coli $\mathrm{O} 32$ and the piglets were killed at 1, 3, 4, 5, 6 and 7 days after challenge. Large numbers of the challenge strain were recovered from the faeces and intestinal contents and two piglets developed diarrhoea $2-3$ days after challenge. The enterocolitis was milder than that observed in the previous litter but of a more persistent nature. Toxaemic changes in internal organs and pneumonic lesions were detected. The results suggest a pathological role for CNF toxin.

THE PATHOGENICITY OF HUMAN AND ANIMAL STRAINS OF FUSOBACTERIUM NECROPHORUM

G. R. Smith, E. A. Thornton, L. M. Wallace, S. E. Gharbia* and H. N. Shah*

Institute of Zoology, Regent's Park, London NWI 4RY and * Department of Oral Microbiology, The London Hospital Medical College, Turner Street, Whitechapel, London E1 2AD

Animal necrobacillosis is caused by Fusobacterium necrophorum (FN) biovar A, but other bacteria are often also present. Though the minimum infective dose (MID) of FN is high ( $>10^{6}$ organisms), rapidly fatal necrobacillosis can be produced in mice by subcutaneous inoculation with pure cultures. Thus for example, in one experiment $14 \times 10^{6}$ organisms fatally infected 25 of 26 mice. The MID can, however, be reduced to $<10$ organisms by suspending the fusobacteria in sub-lethal doses of broth cultures of other bacteria, e.g., Staphylococcus aureus.

Seven human strains of FN were studied. They originated from a neck abscess (1), cerebrospinal fluid (1), and blood cultures (5), but their history of laboratory subculture was unknown. Six of the strains resembled biovar B strains in being much less pathogenic than animal biovar A strains: doses of $10 \times 10^{6}$ to $40 \times 10^{6}$ organisms given subcutaneously to mice produced no more than mild ulcerating lesions that healed rapidly, and infectivity was not appreciably enhanced by $S$. aureus. The seventh strain (A2433), however, in a dose of $c .60 \times 10^{6}$ organisms produced protracted infections with severe lesions, and its infectivity was greatly enhanced by $S$. aureus. The clinical signs and lesions produced in mice by strain A2433 nonetheless differed strikingly from those produced by animal biovar A strains.

The results suggest that the term "necrobacillosis" (FN infection) as used by veterinary and medical microbiologists refers to diseases that differ in important respects.

CAMPYLOBACTER JEJUNI AS AN AEROBE

D. M. Jones and E. M. Sutcliffe

Public Health Laboratory, Withington Hospital, Manchester M20 8LR

When isolated from the gut, Campylobacter jejuni requires microaerobic conditions for successful isolation. However, in the environment this organism undergoes a number of fundamental changes. While it is not able to multiply outside the gut, other than on laboratory media, in the environment $C$. jejuni becomes adapted for prolonged survival. In nonnutritive surroundings, e.g., natural waters, the organism progressively becomes coccal, non-culturable but still viable, and finally dies. In survival experiments when nutrition is available, by making surface viable counts it can be demonstrated that the organism adapts to an aerobic metabolism and that survival is longer in air as opposed to maintained microaerobic conditions. Surviving cells grow on subculture in air or microaerobic conditions with equal facility and the aerobic cultures can be subcultured apparently indefinitely in air. The adoption of aerobic metabolism is accompanied by changes in outer membrane protein profiles on SDS-PAGE and by altered colonial morphology. Serotype reactions and the ability to colonise mice are unaltered.

Aerobic forms of $C$. jejuni are readily produced experimentally but recently we have isolated such aerobic forms directly from environmental water samples.

\section{NUCLEOSIDE-DEPENDENT REPLICATION OF IFDO}

\section{W. Burdon, J. G. Wakeman and P. Nayyar}

Department of Microbiology, The General Hospital, Birmingham $B 46 N H$

IFDO is a novel replicating agent of comparable size to small viruses, which multiplies in cell-free medium and has characteristics in common with prions. It differs from prions in being inactivated by chemicals which alter nucleic acid and by RNAase.

A chemically defined growth medium has been prepared which contains Tween $80, \mathrm{Ca}^{++}, \mathrm{PC}_{4}{ }^{-}, \mathrm{NaCl}$, glutamic acid, trypsin, haemoglobin, horse high density lipoprotein (HDL) or human low density lipoprotein (LDL) and 
nucleosides. Omission of any of the above ingredients except $\mathrm{NaCl}$ prevents replication of the agent.

It is concluded that IFDO replicates by a biological process, and that it is a self-replicating nucleic acid which utilises host-derived protein. Self-assembly of nucleic acid replicas of IFDO is plausible if IFDO is a RNA-ribonuclease of the type exemplified by Escherichia coli RNAase P. IFDO may be the first example of the hypothetical self-replicating RNA presumed to have been involved in the evolution of living agents.

\section{COMPARATIVE DIAGNOSIS OF PEPTIC ULCER DISEASE CAUSED BY HELICOBACTER PYLORI}

C. G. Gemmell, P. Boothman, A. S. Taha*, R. I. Russell* and F. D. Lee $\dagger$

Department of Bacteriology, *Gastroenterology, and †Pathology, Royal Infirmary, Glasgow

The increasing awareness that Helicobacter pylori is important in the development, treatment and recurrence of peptic ulceration has placed greater emphasis on the accuracy of identification of the organism's presence in the management of peptic ulcer disease. A range of tests [culture, histology and urease activity (CLO test) of gastric biopsy material] and serological measurement of specific antibodies were performed on 134 patients in whom peptic ulcer disease was suspected. The sensitivity, specificity and predictive values of histology and urease test compared with culture ranged between $90 \%$ and $97 \%$, whereas the corresponding values for the serological assays were lower (ELISA 61-75\% and latex agglutination $61-67 \%$ ). Concomitant treatment with non-steroidal anti-inflammatory agents (NSAIDs) further reduced the sensitivity and specificity of the serological tests. No difference was seen with the histology or urease test on gastric biopsies from patients on NSAIDs. These findings suggest that $H$. pylori is more reliably diagnosed by culture, histology and CLO-test than by the two serological tests especially in patients taking NSAIDs. However, consideration should be given to the potential benefits in that the latter tests are non-invasive and could be appropriately used as screening tests.

EFFECT OF A REDOX AGENT ON THE SUBGINGIVAL MICROFLORA OF PATIENTS WITH CHRONIC PERIODONTITIS

\section{Wilson, M. Gibson*, D. Strahan* and W. Harvey†}

Microbiology Laboratory, *Department of Periodontology and +Department of Oral and Maxillo-Facial Surgery, Institute of Dental Surgery, 256 Gray's Inn Road, London WC1X 8LD

Redox potentials as low as $-300 \mathrm{mV}$ exist subgingivally in patients with periodontitis enabling the survival of anaerobic periodontal pathogens. By raising the subgingival redox potential it should be possible to create an environment unsuitable for the growth of these bacteria. Therefore, a small-scale trial was carried out to evaluate the effect of a redox agent, methylene blue, on various microbiological and clinical indices of chronic periodontitis.

Methylene blue was applied subgingivally on each of 7 days to 25 test sites in seven patients and the sites were evaluated microbiologically and clinically for 14 days; 25 control sites received water. The test sites showed statistically significant differences from the control sites in terms of changes in microbiological and clinical indices. In the test sites the proportions of anaerobes, gram-negative anaerobes, spirochaetes and motile bacteria decreased, as did the crevicular fluid flow, while the proportions of facultative anaerobes and cocci increased. These changes are indicative of a shift in the microflora towards one that is more compatible with periodontal health.

The encouraging results of this preliminary study suggest that the use of redox agents in the treatment of chronic periodontitis warrants further investigation.

\section{SURFACE-ASSOCIATED MATERIAL FROM \\ PERIODONTOPATHOGENIC BACTERIA STIMULATE BONE RESORPTION BY MULTIPLE PATHWAYS}

\section{B. Henderson, M. Wilson* and S. Meghji}

Maxillofacial Surgery and Oral Medicine Research Unit and *Microbiology Laboratory, Institute of Dental Surgery, 256 Gray's Inn Road, London WC1X $8 L D$

Anaerobic bacteria have been implicated in the alveolar bone loss of periodontitis but the mechanism(s) involved remain unclear. We have extracted the capsules from three periodontopathogens: Actinobacillus actinomycetemcomitans, Porphyromonas gingivalis and Eikenella corrodens by gentle stirring in saline. The extracted material, hereafter referred to as surface-associated material (SAM), was shown to stimulate dose-dependent resportion of murine calvarial bone in vitro with significant resorption being seen with SAM $10 \mathrm{ng} / \mathrm{ml}$.

To determine the mechanism of resorption, bone cultures were stimulated with SAM in the presence of graded concentration of various inhibitors including: (i) indomethacin; (ii) interleukin-1 receptor antagonist (IRAP); (iii) a neutralising antibody to murine TNF- $\alpha$ and (iv) a neutralising antibody to murine IL- 6 . The bone resorbing activity of SAM from $P$. gingivalis was completely inhibited by indomethacin, IRAP and anti-TNF. SAM from $E$. corrodens was moderately inhibited by indomethacin and almost completely inhibited by anti-TNF. In contrast the SAM from $A$. actinomycetemcomitans was unaffected by all inhibitors. Neutralising IL- 6 had no effect on the action of any SAM. Thus multiple pathways of resorption may produce alveolar bone loss in periodontitis.

SERA FROM PERIODONTITIS PATIENTS CONTAIN ANTIBODIES CAPABLE OF INHIBITING BONE BREAKDOWN INDUCED BY SAM FROM PERIODONTOPATHOGENS

\section{S. Meghji, B. Henderson and M. Wilson*}

Maxillofacial Surgery and Oral Medicine Research Unit and *Microbiology Laboratory, Institute of Dental Surgery, 256 Gray's Inn Road, London WC1X 45 8LD

Solubilised surface-associated material (SAM) from a number of periodontopathogens has been shown to be a potent stimulator of bone resorption in the murine calvarial bone resorption assay. Patients with severe generalised periodontitis (SGP) and localised juvenile periodontitis (LJP) have serum antibodies to SAM from such bacteria. Addition of sera from SGP patients containing high titres of antibodies to SAM from $P$. gingivalis to calvarial cultures stimulated with SAM from this organism completely inhibited bone resorption. Sera from patients with low titres of antibody failed to inhibit resorption. High titre sera (containing antibodies to SAM from A. actinomycetemcomitans) from patients with LJP were added to calvaria stimulated with SAM from this organism. Of six high titre sera tested, only four inhibited bone breakdown. Low titre sera were inactive.

Thus, the antibody response to the SAM from periodontopathogens may serve to inhibit or slow alveolar bone resorption but this protective activity appears to be dependent on the idiotypic nature of the antibody response. 
CLINICAL SIGNIFICANCE OF AUXOTROPHIC MUTANS OF PSEUDOMONAS AERUGINOSA IN ADULTS WITH CYSTIC FIBROSIS

R. F. H. Taylor, ${ }^{*}$ M. Warner, ${ }^{*}$ R. C. George, M. E. Hodson and ${ }^{*}$ T. L. Pitt

Royal Brompton Hospital, London SW3 and *Central Public Health Laboratory, Colindale, London NW9

We have reported previously that many sputum isolates of Psetudomonas aeruginosa from patients with cystic fibrosis (CF) are auxotrophic and that the majority of auxotrophs which depend on a single factor, require methionine for growth.

We compared (a) the percentage of auxotrophs in the total bacterial count in sputum from 14 clinically stable CF outpatients and $30 \mathrm{CF}$ in-patients with acute exacerbations, and (b) the antimicrobial susceptibilities of auxotrophic and prototrophic isolates of $P$. aeruginosa retrieved from the same sputum sample of eight CF patients.

Auxotrophic mutants of $P$. aeruginos $a$ were present in the sputum of $40(91 \%)$ of $44 \mathrm{CF}$ adults. The majority ( $>50 \%)$ of colonies were auxotrophic in 22 of 30 patients with acute exacerbations compared with six of 14 stable out-patients $(p=0 \cdot 05)$.

MIC values of 12 anti-pseudomonal agents (four penicillins, three aminoglycosides, ciprofloxacin, colistin, ceftazidime, aztreonam and imipenem) were established for 18 auxotrophs and 15 prototrophs from eight $\mathrm{CF}$ patients. For each patient and antimicrobial agent, the most resistant and most sensitive isolates were identified, giving a total of 192 possible results. For 110 of these 192 , there was $\geqslant 2$-fold difference in MIC values between auxotrophs and prototrophs. Of those isolates that were more sensitive, 40 were prototrophs and 18 auxotrophs, and of those most resistant, nine were prototrophs and 43 auxotrophs $(p<0.001)$. These differences in antimicrobial susceptibilities were observed for all antimicrobial agents tested.
We conclude that in CF the proportion of auxotrophic mutants in $P$. aeruginosa is increased in patients with acute exacerbations and that auxotrophic isolates of $P$. aeruginosa from CF adults are more resistant to anti-pseudomonal agents than prototrophs.

DIFFERENTIATION OF PATIENT ANTIBODY

RESPONSE TO COMMON AND TYPE-SPECIFIC LIPOPOLYSACCHARIDE OF PSEUDOMONAS AERUGINOSA

\section{H. M. Aucken and T. L. Pitt}

Division of Hospital Infection, Central Public Health Laboratory, 61 Colindale Avenue, London NW9 $5 H T$

Two varieties of smooth lipopolysaccharide (LPS) have been identified in Pseudomonas aeruginosa. One LPS determines serotype specificity while the other is common to many serotypes. We have investigated the response of patients to each LPS form. Type-specific serum antibodies were detected by the formation of characteristic ladder bands with a single serotype reference strain in immunoblotting with a panel of 10 frequent serotypes. Antibodies to common LPS produced identical ladder profiles, in immunoblotting, against different serotypes. Sera from 35 patients (23 cystic fibrosis (CF), 11 osteomyelitis and bone infections, one septicaemia) were examined. Of these, $19(54 \%)$ reacted with common LPS antigen and $14(40 \%)$ with a type-specific LPS. Eight patients $(23 \%)$ had antibodies to both forms of LPS. More CF patients $(15$ of $23,65 \%$ ) had antibody to common LPS than osteomyelitis patients $(3$ of $11,27 \%$ ). The results support the view that as $P$. aeruginosa strains in $C F$ patients lose type specific antigens, the response to common LPS antigen becomes dominant. They also suggest that the antibody response to this antigen may be a useful marker of chronic infection with $P$. aeruginosa. 